\title{
ELECTROFORMING, SWITCHING AND MEMORY EFFECTS IN OXIDE THIN FILMS
}

\author{
D. P. OXLEY \\ Department of Physics, Leicester Polytechnic, Leicester, England
}

(Received December 14, 1976)

\begin{abstract}
Experiments on electroforming of Metal-Oxide-Metal thin film sandwiches which have been electroformed to exhibit voltage-controlled negative resistance are summarized and an outline of recent evidence in favour of localized or filamentary conduction is given.

A similar review is given of the experiments on oxide sand wich structures which have been formed to exhibit current-con trolled negative resistance or threshold switching and memory switching. Current theories are reviewed briefly. Finally oxide memory devices are compared with those based upon the chalcogenide glasses.
\end{abstract}

\section{INTRODUCTION}

A wide range of amorphous and crystalline oxide thin films when sandwiched between suitably selected electrodes (usually metal) can be processed so that they exhibit a wide range of interesting electrical properties. Such sandwiches can be made to exhibit voltage-controlled negative resistance (VCNR), current-controlled negative resistance (CCNR), threshold switching, analog memory switching, bistable memory switching and other potentially useful electrical effects. These properties have been reviewed by Dearnaley et $a l^{1}$ and a later bibliography listed by Agarwal ${ }^{2}$ includes some references to switching phenomena. Further papers have appeared since these articles were written and the literature of these effects is now quite extensive. The present paper will give a brief, but hopefully representative, review of this literature summarizing the reported practical significance and compare these switching and memory phenomena with those found in chalcogenide glasses.

\section{FORMING}

The review by Dearnaley et $a l^{1}$ summarized a significant body of experimental evidence to show that:

1) Many metal-amorphous or crystalline oxidemetal thin film sandwich structures could have their electrical properties changed in a radical and irreversible manner by the application of a bias to the electrodes. This process has become known as 'forming'.
2) A large class of metal-amorphous oxide-metal thin film sandwiches could be 'formed' to show an enhanced conductivity in a vacuum and a low frequency VCNR and analog memories. Many workers refer to this process as electroforming.

3) Other forming processes can lead to CCNR and threshold or memory switching.

4) Some oxides can undergo both types of forming.

5) That the models advanced to explain these effects divide into two main groups consisting of schemes envisaging a relatively homogenous modification of the insulator during each type of forming or those envisaging localized or filamentary conduction in the formed state.

The processes leading to the classes of behaviour in (2) and (3) will each be discussed in more detail and the properties of the formed states reviewed.

\section{ELECTROFORMING LEADING TO VCNR}

Devices to be electroformed usually consist of a central insulating layer of thickness in the range $20 \mathrm{~nm}$ to about $1000 \mathrm{~nm}$, a thickness of $100 \mathrm{~nm}$ being typical. The insulator is frequently an amorphous oxide layer prepared either by vacuum deposition or anodic oxidation. The selection for the conducting electrodes to complete the sandwich is limited for the anode (the electrode held at a positive potential during electroforming and subsequent operation) to specific materials; the choice of cathode being less critical. The anode is usually chosen by 
experiment although the balance of evidence ${ }^{1}$ would indicate that inert metal anodes assist in obtaining the electroformed state. Electroforming is carried out in a vacuum. The following results (Figure 1) from the early paper by Verderber $e t a l^{3}$ show the difference between the formed and unformed state for an $\mathrm{Au}-\mathrm{SiO}_{\mathrm{x}}-\mathrm{Al}$ sandwich where the gold electrode is positively biased in a vacuum of better than $10^{-2}$ torr. When the bias is first applied the current is commensurate with that expected on the basis of the conductivity of the unformed insulator, i.e. small. At a critical bias, $V_{F}$, the current increases quite rapidly and irreversibly. Verderber $e t a l^{3}$ report that at a given temperature this voltage $V_{F}$ is reasonably reproducible for nominally identical structures and that it does not depend strongly on the thickness of the insulator; this indicates that electroforming is not simply related to the macroscopic average field. Later work ${ }^{1}$ indicated that $V_{F}$ varied somewhat with insulator and electrode composition. As the bias is cycled at a constant low frequency between 0 and $\sim V_{F}$ the forming progresses until the $I, V$ characteristic becomes reasonably reproducible (Figure 2, curve

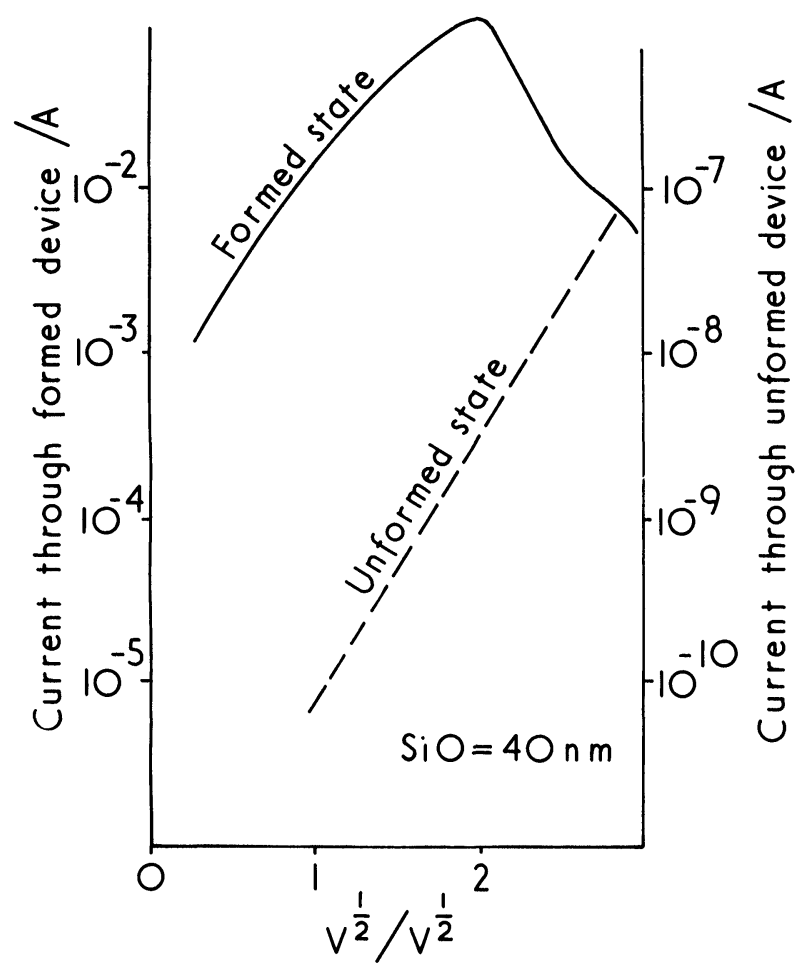

FIGURE 1 From Verderber ${ }^{3}$ et al. showing change in current upon electroforming $\mathrm{Al}-\mathrm{S}_{\mathrm{i}} \mathrm{O}_{\mathrm{x}}-\mathrm{Au}$.

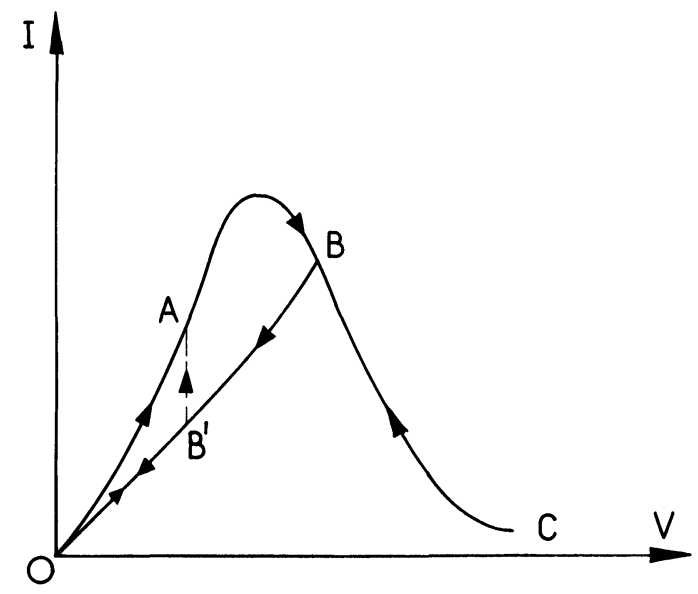

FIGURE 2 I, V characteristic of formed device and an analog memory state (schematic diagram).

$\mathrm{OABC})$. The current in the pronounced region of VCNR is noisy. The VCNR is destroyed if the bias is cycled whilst the device is exposed to air (oxygen seems to be the important gas ${ }^{3}$ ) or if the temperature is reduced to about $100 \mathrm{~K}^{4}$ or if the device is operated under reverse bias. ${ }^{1}$ After such treatments the average conductivity is low and the $I, V$ characteristic non-ohmic. These effects can be reversed. Although prolonged operation in air usually causes degradation of the device. ${ }^{5,7}$

The electroformed structure can be used as an analog memory as described by Simons and Verderber. ${ }^{4}$ They applied a bias $V_{a}>V_{p}$, the voltage for maximum current, to put the device into the region of VCNR. This bias was then removed rapidly, in about $0.1 \mathrm{~ms}$. During this rapid removal, the downward sweep of the $I, V$ locus does not show VCNR (Figure 2). After this process, for a bias below a value $V_{T}$, the $I, V$ characteristic will be that for the previous downward sweep. Simmons and Verderber ${ }^{4}$ claim that this state appeared to be stable indefinitely provided that the bias did not exceed $V_{T}$ and that the memory state was reversible, and that the original low impedance memory state OA could be regenerated by applying a voltage slightly in excess of $V_{T}$. They reported that the sample could exist in any one of a 'continuum' of memory states corresponding to rapid removal of the bias within the VCNR region. The accepted functional form of these characteristics is that given by Simmons and Verderber ${ }^{4}$ viz:

$$
I=K\left(V_{a}\right) \operatorname{Sinh} k\left(V_{a}\right) V
$$

where both $K\left(V_{a}\right)$ and $k\left(V_{a}\right)$ decrease in magnitude 
with increasing $V_{a}$. Typically for $V_{a}=6 \mathrm{~V}$, $K\left(V_{a}\right)=1.1 \times 10^{-3} \mathrm{~A}$ and $k\left(V_{a}\right)=0.5 \mathrm{~V}^{-1}$.

For a given memory state and a bias $V<V_{T}$ then the $I, V$ characteristics are stable as the temperature is decreased with a slight quadratic dependence in the mean conductance $\sigma$. For applied voltages above $1 \mathrm{~V}$ but less than $V_{T}$, Simmons and Verderber. suggest that:

$$
\sigma=6_{0}\left(1+\alpha T^{2}\right)
$$

with

$$
\alpha \approx 10^{-6} K^{-2}
$$

After electroforming devices usually emit electrons and exhibit electroluminescence. Figure 3, after Collins and Gould ${ }^{6}$ shows representative results for the variation in emission current with device bias. Emmer ${ }^{7}$ has reported that all of the electroformed

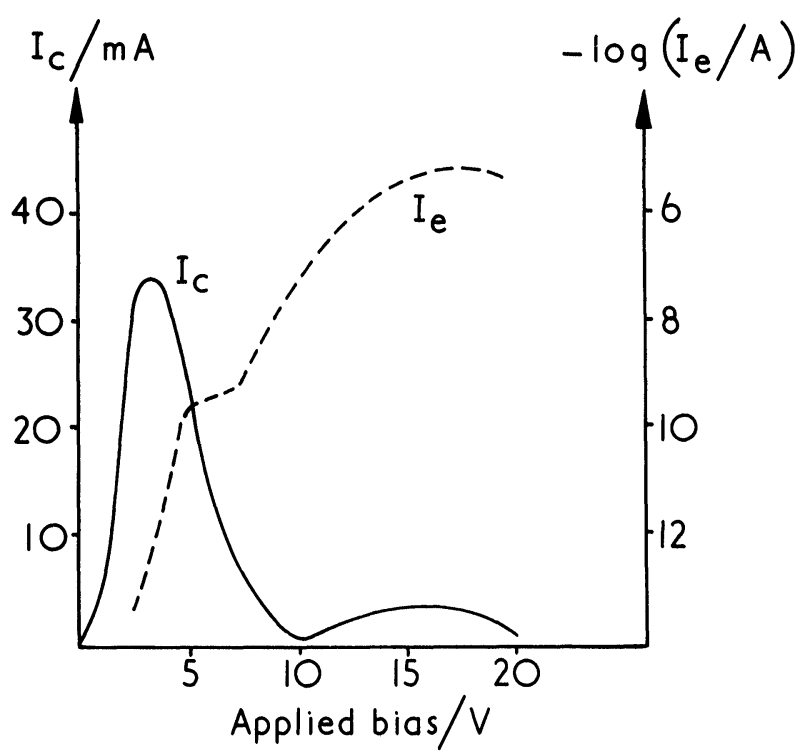

FIGURE 3 From Collins and Gould ${ }^{6}$, showing variation in circulating current $I_{c}$ and emission current $I$ with device bias for $\mathrm{Al}-\mathrm{S}_{\mathbf{i}} \mathrm{O}-\mathrm{Au}$ structure.

$\mathrm{Al}-\mathrm{Al}_{2} \mathrm{O}_{3}-\mathrm{Au}$ structures examined exhibited varying amounts of anode damage which could enhance electron emission. Attempts to use this emission process to infer hotelectron mean-free paths or attenuation lengths have recently been shown to be in error, ${ }^{8}$ and although this analysis was criticized ${ }^{9}$ the authors have replied. ${ }^{10}$

\section{CONDUCTION AND MEMORY STATES AFTER ELECTROFORMING}

Work performed since the review by Dearnaley et al has seriously reduced the credibility of models involving homogenous forming. Single shot pulsed bias studies ${ }^{11}$ have added weight to filamentary approaches. The interpretation of experimental data cited as indicating the existence of local regions of high electric fields near the anode or cathode in electroformed structures has been criticized on simple fundamental grounds, ${ }^{12,13}$ which seriously weakens many band approaches. Equally disconcerting from a band model viewpoint are the experiments of Emmer ${ }^{7}$ giving evidence for localized electron emission.

It would thus appear that the conduction in electroformed structures is localized and that the conduction, memory phenomena, electron emission, electroluminescence and current noise are related to the processes envisaged by Dearnaley et $a l^{14}$ in terms of voltage controlled selective rupture and regrowth of filamentary conduction paths. Dearnaley et $a l^{14}$ suggest that the number of such filaments would be about $5 \times 10^{4} \mathrm{~mm}^{-2}$ with diameters of the order of $1 \mathrm{~nm}$. The detailed nature of the filaments was not specified.

Recently Bischoff and Pagnia ${ }^{15}$ have made gold island structures and report electroforming and d.c. and a.c. I-V characteristics which resemble those in electroformed diodes. They claim that their structures are suitable for electron microscope investigations of the forming and switching process and provide an excellent tool to clarify the fundamental behaviour of electroformed diodes.

\section{BISTABLE SWITCHING AND CCNR}

The detailed forming procedures used to obtain CCNR and bistable switching vary rather more than the procedures used to produce VCNR. Equally the device characteristics after forming are more varied than for devices showing VCNR. Despite these variations many of these forming processes have a common advantage in that forming need not take place in a vacuum. The formed devices are potentially more useful as their properties can be stable under bias in air. Dearnaley et $a l^{1}$ have reviewed the earlier work in this area to show that some oxides can separately exhibit both VCNR and CCNR after suitable forming. This review cites the early reports of Chopra on thermally grown $50 \mathrm{~nm}$ oxide layers of $N b, T_{a}, T i$. Metal-metal oxide- 
metal sandwiches exhibiting rectifying characteristics are formed under reverse bias, by increasing the reverse current to above $1 \mathrm{~mA} \mathrm{~mm} \mathrm{~mm}^{-2}$ to transform the $I, V$ characteristic to a symmetrical shape exhibiting CCNR followed by a region where the dynamic impedance approaches zero (Figure 4). The holding voltage to sustain this state is conveniently small and is independent of oxide thickness and electrode material (as in Ovshinsky ${ }^{16}$ threshold switches for metal electrodes); the CCNR persists at frequencies of up to $1 \mathrm{MHz}$, in contrast with the VCNR in electroformed structures which is limited to lower ( $\lesssim 10 \mathrm{kHz}$ ) frequencies, and on this basis it was argued that the mechanism leading to such CCNR was electronic. Chopra ${ }^{17}$ in his original paper emphasised the reproducibility of his devices compared with those exhibiting VCNR and established their relative insensitivity to ambient air.

The variation in forming conditions leading to CCNR in oxide layers is illustrated by comparison of the previous method of Chopra ${ }^{17}$ with that followed by Hickmott and Hiatt ${ }^{18}$ for their $\mathrm{Nb}-\mathrm{Nb}_{2} \mathrm{O}_{2}-\mathrm{Bi}$ structures. They developed empirically a complex breakdown (forming) procedure using both pulsed and steady but limited currents to produce devices with stable characteristics (Figure 5). The final device has two distinct non-ohmic states with high and low average values of conductance. Switching between these states was described but in view of the reported sporadic nature of the switching, the device degradation under sinusoidal drive at $100 \mathrm{kHz}$, and the gener general absence of long term stability in any state,

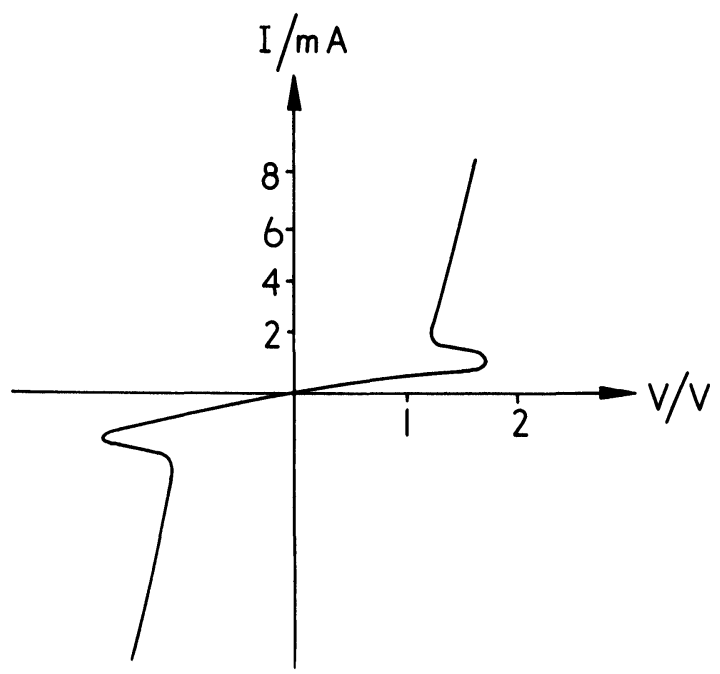

FIGURE 4 Showing CCNR in Nb-Nb oxide-Au structure. After Chopra ${ }^{17}$.

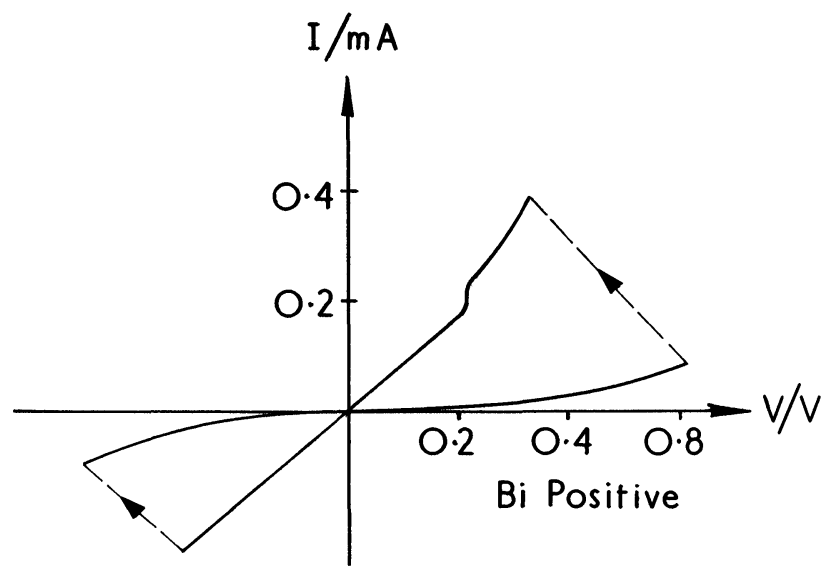

FIGURE 5 Showing memory states for $\mathrm{Nb}-\mathrm{Nb}_{2} \mathrm{O}_{5}-\mathrm{Bi}$ structure. After Hickmott and Hiatt ${ }^{18}$.

they are of little direct interest for memory application in reported form. It is of interest to note however that Hickmott and Hiatt ${ }^{18}$ confirmed earlier reports ${ }^{19}$ that the forming results from the modification of a very small region of the oxide of less than $10^{-3} \mathrm{~mm}^{2}$ in contrast with Chopra ${ }^{17}$ who suggested that the whole structure was active in his devices. Further variations in forming methods and characteristics of the formed devices are reported in the work of Basavaiah and Park ${ }^{20}$ for $\mathrm{Nb}-\mathrm{Nb}_{2} \mathrm{O}_{5}$-Bi junctions. They used a simple forming procedure, applying a bias of $+30 \mathrm{~V}$ via a $50 \mathrm{~K} \Omega$ resistor to the bismuth electrode to reduce the resistance from about $10^{7} \Omega$ to about $5 \mathrm{~K} \Omega$. Memory switching between two states with a binary signal ratio of $8: 1$ for more than $10^{6}$ operations was reported. Typical switching times were $1 \mu \mathrm{s}$ and $20 \mu \mathrm{s}$ from the high to low and low to high resistance states respectively. Conduction in the formed state was associated with the modification of a small $\left(\sim 2 \mu^{2}\right)$ region in the oxide layer which was observed on the top bismuth film. It was suggested that the conduction in the high resistance state was related to a Schottky mechanism whereas that in the low conductivity state was not identified. More recently Lalevic et $a l^{21}$ reported a further variation; this work used $\mathrm{Nb}-\mathrm{Nb}_{2}-\mathrm{O}_{5}-\mathrm{Nb}$ structures with $\mathrm{Nb}$ doped amorphous $\mathrm{Nb}_{2} \mathrm{O}_{5}$ films. Forming was initiated using a bias of $14 \mathrm{~V}$ and a current density of $1.34 \mathrm{~mA} \mathrm{~mm}^{-2}$. During this process the resistivity changed from $1.4 \times 10^{10} \Omega \mathrm{m}$ to $2.9 \times 10^{8} \Omega \mathrm{m}$. At this state a reduced bias of $1.25 \mathrm{~V}$ at a current of $3.0 \mathrm{~mA}$ was necessary to bring the device to a final state with a resistivity of $5 \times 10^{7} \Omega \mathrm{m}$. Repetitive switching between bistable states was then claimed 


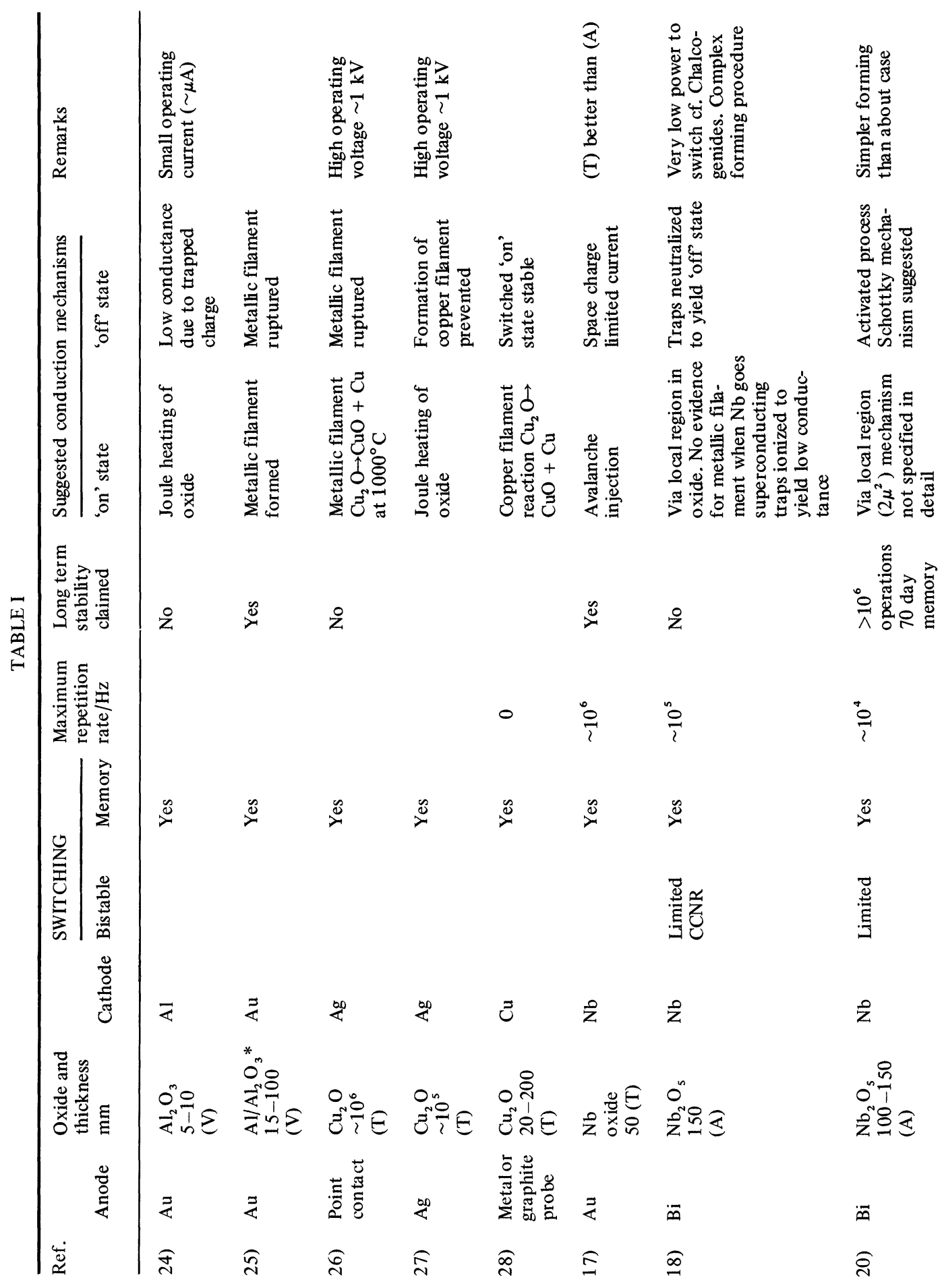



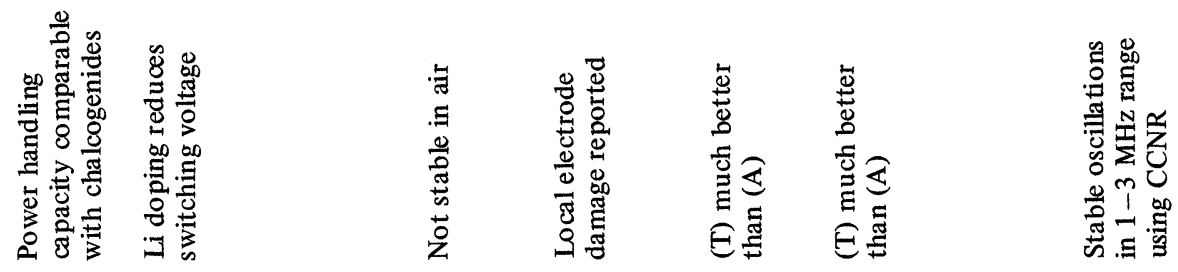

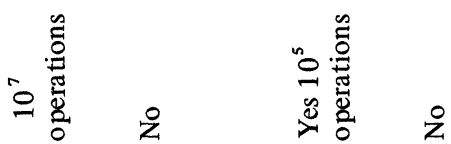

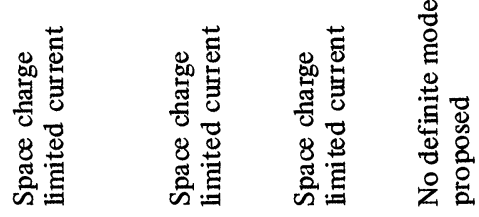

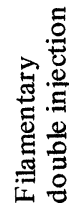

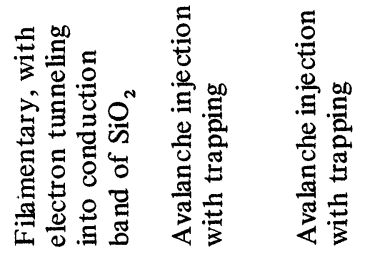

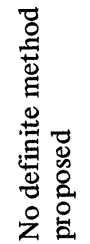

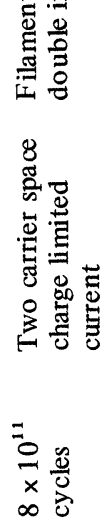

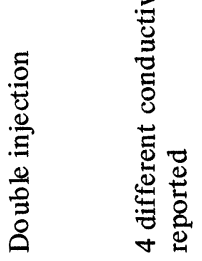

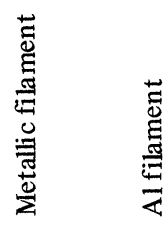

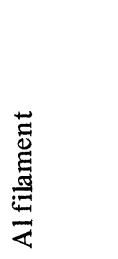

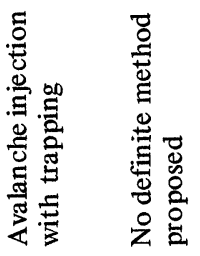

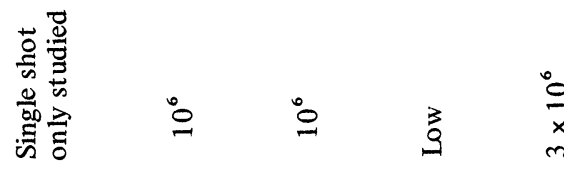

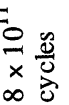

$\stackrel{+}{\circ}$

$\sum_{\infty}^{\infty} \sum_{\infty}^{\infty}$

$\stackrel{\leftrightarrow}{\varnothing}$

$\stackrel{2}{\circ}$

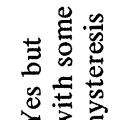

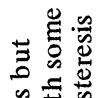

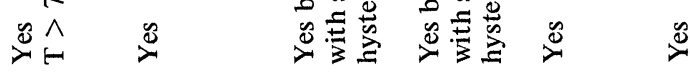

z

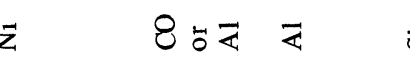

룬

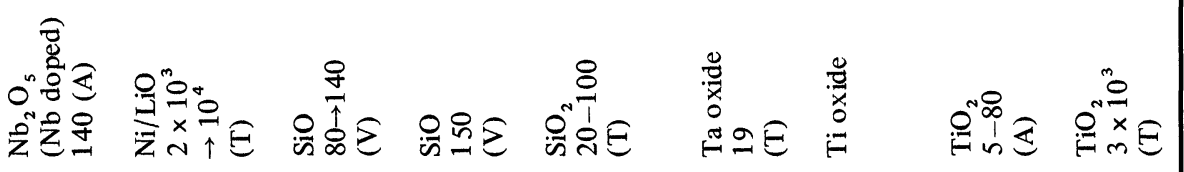

is

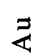

$F \quad F$

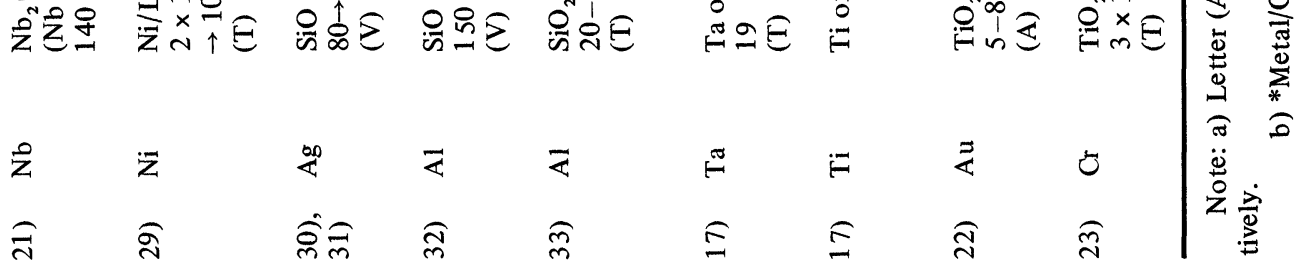


with the switching state characterized by a CCNR. The observed delay time in switching was $>1 \mathrm{~ms}$ which was used to argue a double-injection model of the switching mechanism. They also claimed that their devices could switch in times and sustain power levels which compared favourably with amorphous chalcogenide thin film structures.

The earlier work by Chopra ${ }^{17}$ included reports of high frequency CCNR in formed $\mathrm{Ti}-\mathrm{TiO}_{2}-\mathrm{Au}$ structures. The later data obtained by Soukup ${ }^{22}$ on $\mathrm{Ti}-\mathrm{TiO}_{2}$-Au structures who reported CCNR only under slowly varying bias would appear to be in conflict. Recently Taylor and Lalevic ${ }^{23}$ have obtained stable oscillations in the $1-3 \mathrm{MHz}$ range using the CCNR in a $\mathrm{Ti}-\mathrm{TiO}_{2}-\mathrm{Cr}$ device. These variations may be associated with electrode composition or forming procedures. Taylor and Lalevic ${ }^{25}$ suggest that the measured $I, V$ characteristics for their devices are in agreement with the theory of filamentary double injection of space charge limited current.

Switching has also been reported by other workers, some using other oxides (Table 1) and it can be seen that a clear theoretical understanding has yet to emerge. For memory switching the balance of evidence perhaps points to filamentary conduction in the on state whilst for the threshold switches the picture is less clear.

\section{COMPARISON WITH OVSHINSKY DEVICES}

Ovshinsky ${ }^{16}$ switches, both memory and threshold, are based upon layers of chalcogenide glass, sandwiched between suitable electrodes. The mechanism of operation of the memory switch has for some time been understood to be associated with the growth of a highly conducting polycrystalline filament during the lock-on process whilst revitrification of the polycrystalline region occurs during the reset process to a lower conductance state. Etching techniques have verified these ideas in detail and led to improved device performance.

Threshold switching, using rather more stable, chalcogenides, has only recently been understood in detail. Petersen and Adler ${ }^{34}$ have cited excellent evidence to show that in the case of chalcogenide threshold switches the conduction in the on state is that for a semi-conductor whose electronic band structure is essentially unchanged from the off state, but in which a concentration of about $10^{20}$ electrons $\mathrm{m}^{-3}$ yields the high conductivity. They have refined the accepted filamentary model of conduction by measuring the filament size as a function of current.
This was achieved using velocity saturation effects in amorphous/crystalline $\mathrm{Si}$ heterojunctions and transient on state conductivity measurements. They emphasize that at a high current density in a $1-2 \mu \mathrm{m}$ layer of chalcogenide glass the 'filament' diameter will $\mathrm{be} \approx 50 \mu \mathrm{m}$ provided that pore saturation is not evident, hence their comment "Note that the filament .... has the appearance of a pancake rather than a long narrow channel". Such filament diameters lead to relatively low $\left(<100^{\circ} \mathrm{C}\right)$ pore temperatures and may assist in long term stability.

Reference to Table 1 shows that oxide sandwich structures can exhibit threshold and memory switching. However, in view of the present limited use of chalcogenide switches which, most importantly are of established compatibility with silicon technology, are relatively more reliable, and also better understood, it seems unlikely that oxide switches will be sold in the next decades. It will be interesting from a fundamental viewpoint to continue to examine switching in oxides as a clear theoretical position has yet to emerge. For the development of any possible future application of oxide switches it is perhaps best to attempt to understand the memory switches. These can be used, like chalcogenide switches, to perform read-mostly functions not accessible by silicon technology alone. ${ }^{35}$

\section{REFERENCES}

1. G. Dearnaley, A. M. Stoneham and D. V. Morgan, "Electrical phenomena in amorphous oxide films", Repts. Prog. Phys., 33, 1124 (1970).

2. V. K. Agarwal, "Breakdown conduction in thin dielectric films: a bibliographical survey", Thin Solid Films, 24, 55 (1974).

3. R. R. Verderber, J. G. Simmons and B. Eales, "Forming processes in evaporated SiO thin films", Phil. Mag., 16, 1049 (1967).

4. J. G. Simmons and R. R. Verderber, "New conduction and reversible memory phenomena in thin insulating films", Proc. Roy. Soc., A301, 79 (1967).

5. P. D. Greene, E. L. Bush and I. R. Rawlings, "The forming process in metal-insulator-metal thin film memory and cold cathode devices", Proc. Symp. on Deposited Thin Dielectrics, Montreal ed., 167 (1969)

6. R. A. Collins and R. D. Gould, "Hot electron transport and emission in $\mathrm{Au}-\mathrm{SiO}-\mathrm{Au}$ thin film cathodes", SolidState Electron, 14, 805 (1971).

7. I. Emmer, "Conducting filaments and voltage-controlled negative resistance in $\mathrm{Al}-\mathrm{Al}_{2} \mathrm{O}_{3}-\mathrm{Au}$ structures with amorphous dielectric", Thin Solid Films, 20, 43 (1974).

8. D. P. Oxley and R. E. Thurstans, "Criticism of some hotelectron atten uation length measurements", Thin Solid Films, 26, 157 (1975) 
9. R. A. Collins and R. D. Gould, "Hotelectron attenuation measurements: comments relating to recent criticisms", Thin Solid Films, 30, L1 (1975).

10. D. P. Oxley and R. E. Thurstans, "A reply to 'Hotelectron at tenuation measurements: comments relating to recent criticisms", Thin Solid Films, 16, L5 (1975).

11. R. E. Thurstans, P. C. Wild and D. P. Oxley, "Enhanced forming in $\mathrm{Al}-\mathrm{SiO}_{\mathrm{x}}$-Au structures under pulsed bias", Thin Solid Films, 20, 281 (1974).

12. D. P. Oxley and P. C. Wild, "Potential distribution in electro-formed M1 M and M1 M1 M structures", Thin Solid Films, 23, 353 (1974).

13. D. P. Oxley and D. A. Bean, "Comments on 'Experiments on M-I-M-I-M triode structures using $\mathrm{SiO}_{\mathrm{X}} / \mathrm{B}_{2} \mathrm{O}_{3}$ as the insulating material", Int. J. Electron, 44, No. 3, 309 (1976).

14. G. Dearnaley, D. V. Morgan and A. M. Stoneham, "A model for filament growth and switching in amorphous oxide films", Journ. of Non-Cryst. Solids, 4, 593 (1970).

15. M. Bischoff and H. Pagnia, "Electroluminescence spectra from gold island structure thin films", Thin Solid Films, 29, 303 (1975).

16. S. R. Ovshinsky and H. Fritzche, "Amorphous semiconductors for switching, memory, and imagining applications", IEEE Trans. Electron. Dev., Ed. 20, No. 2, 91 (1973).

17. K. L. Chopra, "Avalanche-Induced Negative Resistance in Thin Oxide Films", J. Appl. Phys., 36, 184 (1965).

18. T. W. Hickmott and W. R. Hiatt, "Electrode effects and bistable switching of amorphous $\mathrm{Nb}_{2} \mathrm{O}_{5}$ diodes", Solid-State Electron, 7, 1033 (1970).

19. T. W. Hickmott, "Electroluminescence, bistable switching and dielectric breakdown of $\mathrm{Nb}_{2} \mathrm{O}_{5}$ diodes", J. Vac. Sci. \& Tech., Vol. 6 No. 5, 828 (1969),

20. S. Basavaiah and K. C. Park, "Bistable Switching and Conduction Mechanisms in Nb- $\mathrm{Nb}_{2} \mathrm{O}_{5}$ - $\mathrm{Bi}$ Junctions", IEEE Trans. Electron. Dev., Ed. 20, No. 2, 150 (1973).

21. B. Lalevic, N. Fuschillo and W. Slusark (Jr.), "Switching in $\mathrm{Nb}-\mathrm{Nb}_{2} \mathrm{O}_{5}$ amorphous films", IEEE Trans. Electron. Dev., Ed. 22, 965 (1975).
22. R. J. Soukup, "Observations of negative resistance in Ti-TiO 2 -Au diodes", J. Appl. Phys., 43 No. 8, 3431 (1972).

23. G. Taylor and B. Lalevic, "R.F. relaxation oscillation in polycrystalline $\mathrm{TiO}_{2}$ thin films", Solid-State Electron, 19, 669 (1976).

24. A. Roybardhan, P. C. Srivastava and D. L. Bhattacharya, "Negative resistance and bistable switching in very thin $\mathrm{Al}_{2} \mathrm{O}_{3}$ films", Thin Solid Films, 24541 (1974).

25. H. Birey, "High-ficld transport properties of aluminiumembedded aluminium oxide films", App. Phys. Lett., 23, No. 6, 316 (1973).

26. E. L. Cook, "Model for the resistive-conductive transition in reversible resistance-switching solids", J. Appl. Phys., 41 No. 2, 551 (1970).

27. M. J. Zarabi and M. Satyam, "Switching in copper oxide", J. Appl. Phys., 45 No. 2, 775 (1974).

28. D. V. Morgan and M. J. Howes, "Electroforming and switching in copper oxide films", Phys. Stat. Sol. (a), 21, 191 (1974).

29. N. Fuschillo, B. Lalevic and B. Leung, "High-field transport in $\mathrm{NiO}$ and $\mathrm{Ni}_{1-x} \mathrm{Li}_{\mathbf{x}} \mathrm{O}$ thin films", Solid-State Electron, 19, 209 (1976).

30. S. Manhart, "Memory switching in $\mathrm{SiO}$ films with $\mathrm{Ag}$ and Co electrodes", J. Phys.D: Appl. Phys., 6, 82 (1973).

31. S. Manhart, "Conduction and switching characteristics of $\mathrm{SiO}$ films with $\mathrm{Al}$ and $\mathrm{Ag}$ electrodes", Journ. Non-Cryst. Solids, 11, 293 (1973).

32. D. V. Morgan and M. J. Howes, "Threshold and memory switching in silicon oxide films", Thin Solid Films, 20, S7 (1974).

33. M. Shatzkes, M. Av-Ron and R. M. Anderson, "On the nature of conduction and switching in $\mathrm{SiO}_{2}$ ", J. Appl. Phys., 45, No. 5, 2065 (1974).

34. K. E. Petersen and D. Adler, "On state of amorphous threshold switches”, J. Appl. Phys., 47, No. 1, 256 (1976).

35. J. Tauc, "Amorphous semiconductors", Physics Today, Oct. (1976). 

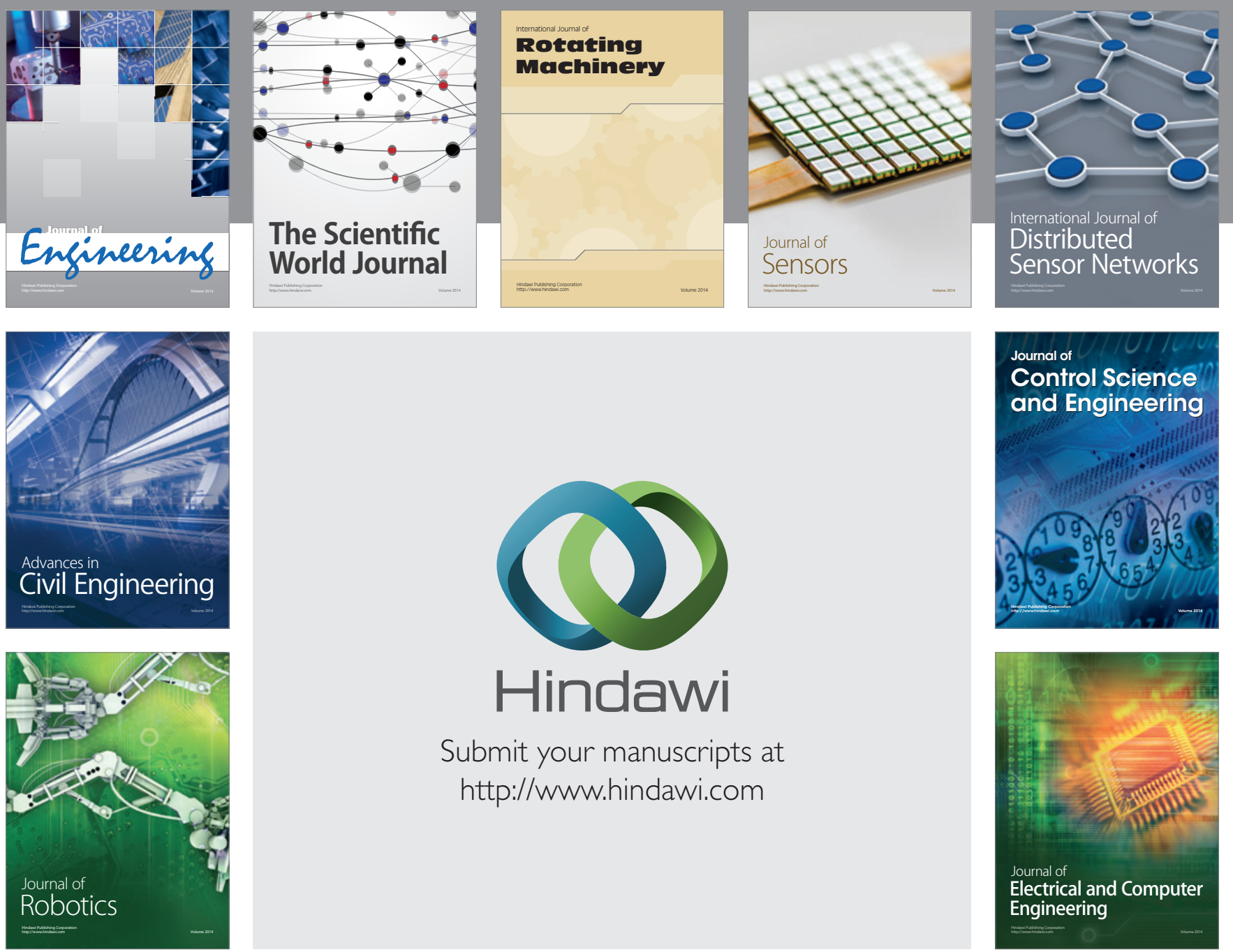

Submit your manuscripts at

http://www.hindawi.com
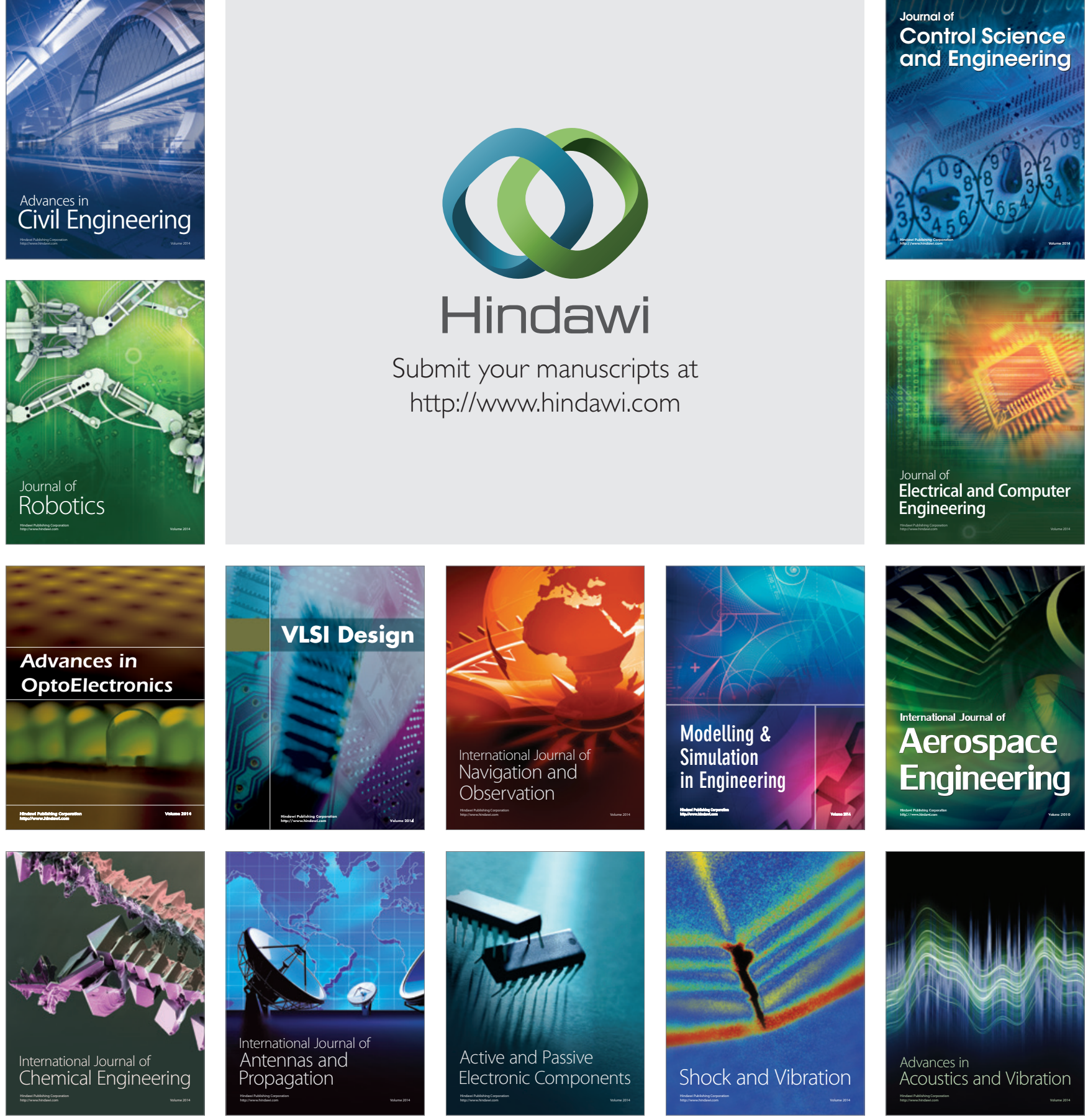